\title{
Erratum to: Return to work among self-employed cancer survivors
}

\author{
Steffen Torp $^{1}$ - Jonn Syse ${ }^{1}$ - Alain Paraponaris ${ }^{2}$ - Sævar Gudbergsson ${ }^{1}$
}

Published online: 15 December 2016

(C) Springer Science+Business Media New York 2016

Erratum to: J Cancer Surviv

DOI 10.1007/s11764-016-0578-8

In the original publication of Table 1 , the columns are misaligned and this makes the table with irrelevant data in the columns.

The original article was corrected.

The online version of the original article can be found at doi:10.1007 /s11764-016-0578-8.

Steffen Torp

steffen.torp@hbv.no

1 Department of Health Promotion, University College of Southeast Norway, PO Box 4, 3199 Borre, Norway

2 Aix-Marseille School of Economics (Aix-Marseille University, GREQAM) \& Southeastern Health Observatory (ORS PACA), Aix-Marseille, France 
Table 1 Clinical, sociodemographic and work characteristics of salaried and self-employed cancer survivors

\begin{tabular}{|c|c|c|c|c|c|c|c|c|}
\hline & \multicolumn{2}{|c|}{ Total $(n=1115)$} & \multicolumn{2}{|c|}{ Salaried $(n=1027)$} & \multicolumn{2}{|c|}{ Self-employed $(n=88)$} & \multirow[b]{2}{*}{$P$} & \multirow[b]{2}{*}{ Effect size } \\
\hline & $n(\%)$ & Mean (SD) & $n(\%)$ & Mean (SD) & $n(\%)$ & Mean (SD) & & \\
\hline \multicolumn{9}{|l|}{ Clinical factors } \\
\hline Treatment & & & & & & & 0.17 & \\
\hline Chemotherapy & $573(51)$ & & $534(52)$ & & $39(44)$ & & & \\
\hline Other treatments & $542(49)$ & & $493(48)$ & & $46(56)$ & & & \\
\hline Comorbidity & & & & & & & 0.08 & \\
\hline No & $655(59)$ & & $611(60)$ & & $44(50)$ & & & \\
\hline Yes & $460(41)$ & & $416(40)$ & & $44(50)$ & & & \\
\hline Time since diagnosis (months) & & $28.9(16.1)$ & & $28.7(15.3)$ & & $32.1(23.6)$ & 0.19 & \\
\hline \multicolumn{9}{|l|}{ Sociodemographic factors ${ }^{\mathrm{a}}$} \\
\hline Sex & & & & & & & $<0.001$ & 0.49 \\
\hline Male & $338(31)$ & & $291(29)$ & & $47(53)$ & & & \\
\hline Female & $765(69)$ & & $724(71)$ & & $41(47)$ & & & \\
\hline Age (years) & & $51.8(8.3)$ & & $51.7(8.4)$ & & $53.3(6.7)$ & 0.04 & 0.19 \\
\hline Annual income & & & & & & & 0.86 & \\
\hline$\leq \mathrm{NOK} 500,000$ & $876(83)$ & & $807(83)$ & & $69(84)$ & & & \\
\hline$>\mathrm{NOK} 500,000$ & $174(17)$ & & $161(17)$ & & $13(16)$ & & & \\
\hline Education & & & & & & & 0.02 & 0.26 \\
\hline$\leq 12$ years & $546(49)$ & & $492(48)$ & & $54(61)$ & & & \\
\hline$>12$ years & $557(51)$ & & $523(52)$ & & $34(39)$ & & & \\
\hline Civil status & & & & & & & 0.19 & \\
\hline Non-paired & $245(22)$ & & $231(23)$ & & $14(17)$ & & & \\
\hline Paired & $862(78)$ & & $791(77)$ & & $7184)$ & & & \\
\hline Children $<18$ years & & & & & & & 0.50 & \\
\hline No & $761(71)$ & & $699(70)$ & & $62(74)$ & & & \\
\hline Yes & 317 (29) & & $295(30)$ & & $22(26)$ & & & \\
\hline \multicolumn{9}{|l|}{ General work factors $^{\mathrm{b}}$} \\
\hline Hours worked per week & & & & & & & 0.38 & \\
\hline$<37 \mathrm{~h}$ & $301(28)$ & & $281(28)$ & & $20(24)$ & & & \\
\hline$\geq 37 \mathrm{~h}$ & $790(72)$ & & $725(72)$ & & $65(76)$ & & & \\
\hline Physical working environment & & & & & & & 0.02 & 0.27 \\
\hline Non-manual work & 837 (77) & & $782(78)$ & & $55(66)$ & & & \\
\hline Manual work & $251(23)$ & & $223(22)$ & & $28(34)$ & & & \\
\hline \multicolumn{9}{|c|}{ Psychosocial working environment $^{c}$} \\
\hline Mental demands & & $3.2(1.0)$ & & $3.2(1.0)$ & & $3.0(1.1)$ & 0.06 & \\
\hline Decision latitude & & $4.1(0.8)$ & & $4.0(0.8)$ & & $4.3(0.8)$ & 0.003 & 0.37 \\
\hline
\end{tabular}

${ }^{a}$ At the time of the survey

${ }^{\mathrm{b}}$ At the time of diagnosis

${ }^{\mathrm{c}}$ High scores indicate high mental demands and high decision latitude 